\title{
EFFECT OF LOADING RATE ON THE FRACTURE BEHAVIOUR OF FIBRE REINFORCED CONCRETE
}

\author{
STEFIE J. STEPHEN ${ }^{*}$, RAVINDRA GETTU ${ }^{\dagger}$ and BENNY RAPHAEL ${ }^{\dagger \dagger}$ \\ Indian Institute of Technology Madras \\ Chennai, India \\ e-mails: stefie.j.s@gmail.com; ${ }^{\dagger}$ gettu@iitm.ac.in; ${ }^{\dagger \dagger}$ benny@iitm.ac.in
}

Keywords: Fibre reinforced concrete, notched beam test, flexural toughness, load rate effect, inverse analysis

\begin{abstract}
Fibre reinforced concrete (FRC) is used in applications such as tunnel lining, pavements, bridge deck overlays and floor slabs, where the loads are sustained as well as applied over short durations. In this context, the effect of loading rate, in the quasi-static range, on the flexural properties of FRC have been studied. The three-point bending test of a notched beam, under crack mouth opening displacement (CMOD), is used to determine the post-peak flexural response of the material at loading rates covering 4 orders of magnitude. Two types of fibres are investigated namely, hooked ended steel fibres and polypropylene fibres. The experimental results confirm that the flexural strength increases with an increase in CMOD rate, as expected. It is also seen that the flexural toughness parameters increase with the CMOD rate. Stress-crack opening relations are obtained from inverse analysis using the load-CMOD curves and the probabilistic global search Lausanne (PGSL) optimization algorithm. The study of the variation in the $\sigma$-w curves with CMOD rate indicate that the tensile strength associated with crack initiation is dependent of the rate but the post-cracking cohesive stresses are not affected significantly.
\end{abstract}

\section{INTRODUCTION}

Fibre reinforced concrete (FRC) is widely used in pavements, slab-on-grade, bridge decks and tunnel linings because of its crack resistance. The structural design for such applications generally requires the constitutive relation in tension or some measure of the toughness. A common basis for the flexural toughness characterization is the bending test of a prism [1, 2] under quasi-static loading. The load-crack mouth opening displacement curve (P-CMOD) obtained from the threepoint bending test has also been used to derive the tensile fracture properties of the material through inverse analysis [3-10]. The tensile constitutive relation is normally represented by a stress-crack opening $(\sigma-w)$ curve, which can be modeled as linear, bilinear, trilinear or even multilinear. In this work, bilinear and trilinear $\sigma-\mathrm{W}$ curves are obtained from the inverse analyses.

The compressive strength and tensile properties of concrete have shown to exhibit a dependency on the loading rate [11-18]. Since FRC is used in applications where the members have to resist loads ranging from dynamic to sustained loading, it would be useful to incorporate such rate effects in the analysis and design of FRC structures.

To examine the rate effects on the $\sigma-\mathrm{w}$ curve of FRC, tests have been performed here at crack mouth opening displacement (CMOD) rates covering 4 orders of magnitude (mainly slow loading rates rather than impact). 


\section{EXPERIMENTAL PROGRAMME}

The procedure used in this work for the three-point bending test on notched beams conforms to EN 14651:2005 [2]. The dimensions of the specimen are $150 \times 150 \times 700$ $\mathrm{mm}$, with a span of $500 \mathrm{~mm}$; a notch of $25 \mathrm{~mm}$ depth is cut at the mid-span (Figure 1). The beam is loaded such that the direction of casting is perpendicular to the loading direction.

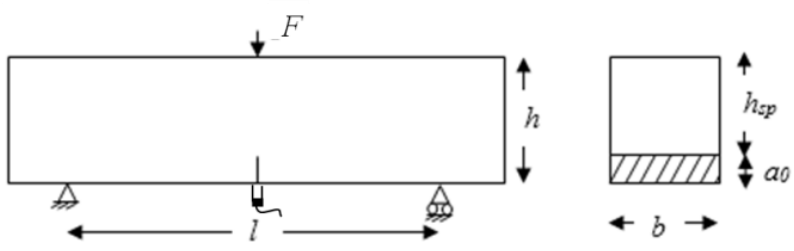

Figure 1: Testing configuration.

The surfaces of the specimens are sealed with aluminium foil to avoid drying during the test. The CMOD is measured using a clip gauge mounted across the crack faces. The test is performed in a $1 \mathrm{MN}$ MTS closed loop servo-hydraulic system with a $100 \mathrm{kN}$ load cell, under constant CMOD rate; the CMOD rates used are 10, 1, 0.1 and $0.01 \mu \mathrm{m} / \mathrm{s}$.

Two types of fibres are studied, namely hooked-ended steel fibres (SF) and polypropylene fibres (PF); the important characteristics of which are given in Table 1. The fibre volume fraction is $0.4 \%$, in both cases. The design cube compressive strength of concrete is $35 \mathrm{MPa}$.

Table 1: Properties of the fibres

\begin{tabular}{lcc}
\hline Material & Steel & Polymer \\
\hline Fibre type & $\begin{array}{c}\text { Hooked- } \\
\text { ended }\end{array}$ & Polypropylene \\
\hline $\begin{array}{l}\text { Specific gravity } \\
\text { (g/cc) }\end{array}$ & 7.8 & 0.92 \\
\hline $\begin{array}{l}\text { Tensile strength } \\
\text { (MPa) }\end{array}$ & 1225 & 620 \\
\hline Length $(\mathrm{mm})$ & 60 & 40 \\
\hline Diameter $(\mathrm{mm})$ & 0.75 & 0.44 \\
\hline
\end{tabular}

\section{EXPERIMENTAL RESULTS AND DISCUSSIONS}

The experimental results are shown for SFRC and PFRC (as mean curves from 3 specimens) in Figures 2 and 3. Note that the notation used indicates the strength of the concrete, type of fibre, dosage in $\mathrm{kg} / \mathrm{m}^{3}$ and the CMOD rate in $\mu \mathrm{m} / \mathrm{s}$; e.g., M35SF30_0.1 gives the response for the $35 \mathrm{MPa}$ grade concrete with steel fibres at $30 \mathrm{~kg} / \mathrm{m}^{3}$ dosage tested at $0.1 \mu \mathrm{m} / \mathrm{s}$. The results indicate that the flexural toughness generally increases with an increase in loading rate. However, in the case of SFRC, at the highest loading rate $(10 \mu \mathrm{m} / \mathrm{s})$, the toughness seems to be lower than at $1 \mu \mathrm{m} / \mathrm{s}$. This may be due to the rupture of some fibres or multiple crack fronts at higher loading rates instead of fibres being pulled out.

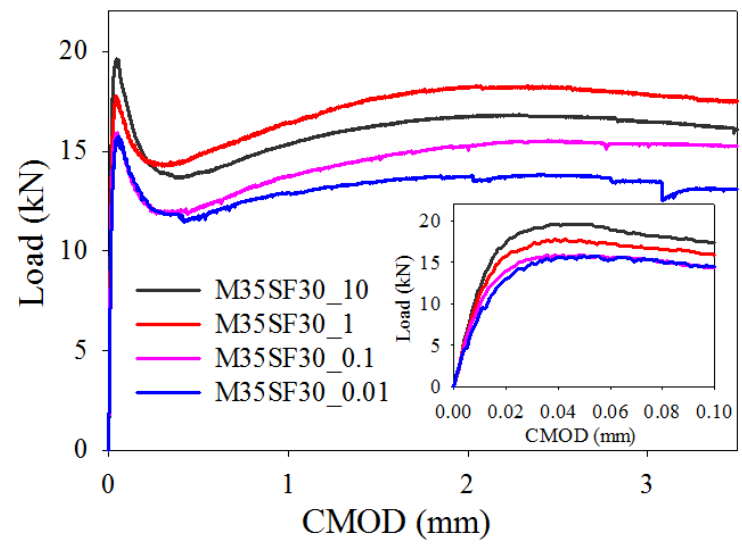

Figure 2: Load-CMOD responses of SFRC at different loading rates.

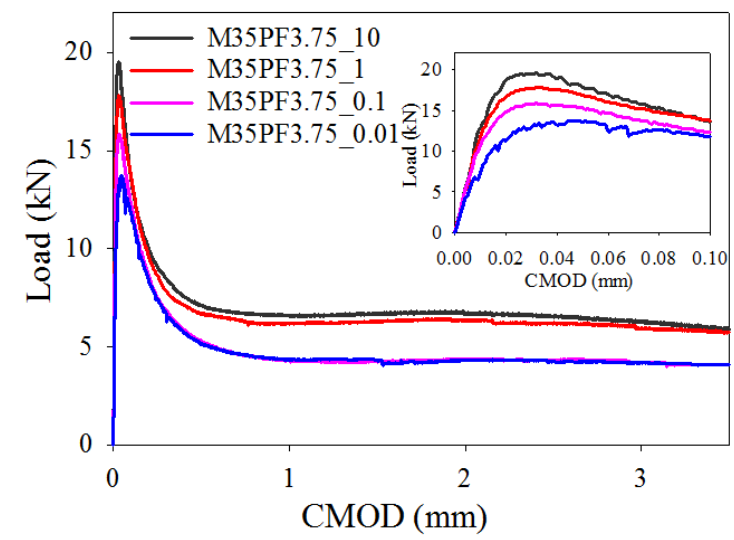

Figure 3: Load-CMOD responses of PFRC at different loading rates. 


\subsection{Limit of proportionality or flexural strength}

The limit of proportionality (LOP) values were calculated according to EN 14651: 2005 [2] (see data in Figure 4).

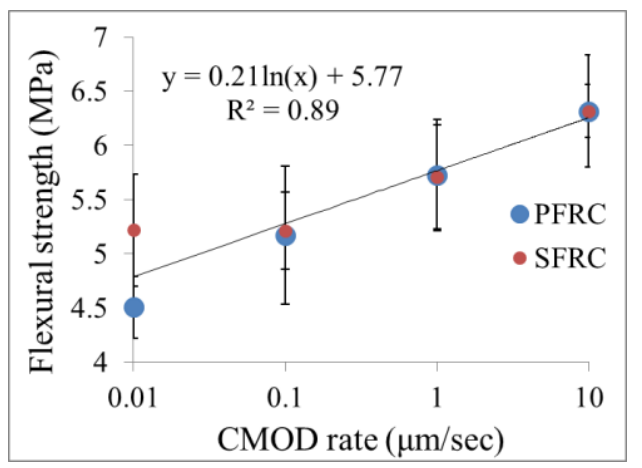

Figure 4: Flexural strength versus CMOD rate
The values have been calculated here using the nominal beam sections. It is seen that the flexural strength increases by $25 \%$ with increase in loading rate There is no influence of the fibre type observed, as expected.

\subsection{Residual flexural strength}

The residual flexural strengths at different CMODs have also been calculated as per EN 14651: 2005. For a particular CMOD, the residual flexural strength increases with an increase in loading rate, implying that the toughness of FRC increases with the loading rate (see Tables 2 and 3); the exception being the SFRC at $10 \mu \mathrm{m} / \mathrm{s}$.

Table 2: Toughness parameters at different loading rates for SFRC

\begin{tabular}{ccccc}
\hline \multirow{2}{*}{$\begin{array}{c}\text { CMOD rate } \\
(\mu \mathrm{m} / \mathrm{s})\end{array}$} & \multicolumn{4}{c}{ Residual flexural strength at the CMOD of } \\
\cline { 2 - 5 } & $0.5 \mathrm{~mm}$ & $1.5 \mathrm{~mm}$ & $2.5 \mathrm{~mm}$ & $3.5 \mathrm{~mm}$ \\
& $f_{R, 1}$ & $f_{R, 2}$ & $f_{R, 3}$ & $f_{R, 4}$ \\
\hline 10 & $4.45( \pm 0.9)$ & $5.21( \pm 1.2)$ & $5.36( \pm 1.3)$ & $5.15( \pm 1.3)$ \\
\hline 1 & $4.74( \pm 1.2)$ & $5.65( \pm 1.4)$ & $5.82( \pm 1.5)$ & $5.62( \pm 1.4)$ \\
\hline 0.1 & $3.88( \pm 0.9)$ & $4.70( \pm 0.9)$ & $4.96( \pm 0.9)$ & $4.88( \pm 0.8)$ \\
\hline 0.01 & $3.75( \pm 0.8)$ & $4.31( \pm 1.0)$ & $4.41( \pm 1.0)$ & $4.19( \pm 1.0)$ \\
\hline
\end{tabular}

Table 3: Toughness parameters at different loading rates for PFRC

\begin{tabular}{ccccc}
\hline \multirow{2}{*}{$\begin{array}{c}\text { CMOD rate } \\
(\mu \mathrm{m} / \mathrm{s})\end{array}$} & \multicolumn{4}{c}{ Residual flexural strength at the CMOD of } \\
\cline { 2 - 5 } & $0.5 \mathrm{~mm}$ & $1.5 \mathrm{~mm}$ & $2.5 \mathrm{~mm}$ & $3.5 \mathrm{~mm}$ \\
& $f_{R, 1}$ & $f_{R, 2}$ & $f_{R, 3}$ & $f_{R, 4}$ \\
\hline 10 & $2.27( \pm 0.2)$ & $2.14( \pm 0.1)$ & $2.10( \pm 0.1)$ & $1.89( \pm 0.1)$ \\
\hline 1 & $2.15( \pm 0.4)$ & $2.02( \pm 0.3)$ & $1.99( \pm 0.3)$ & $1.84( \pm 0.2)$ \\
\hline 0.1 & $1.70( \pm 0.4)$ & $1.37( \pm 0.4)$ & $1.39( \pm 0.3)$ & $1.31( \pm 0.3)$ \\
\hline 0.01 & $1.66( \pm 0.1)$ & $1.39( \pm 0.1)$ & $1.36( \pm 0.03)$ & $1.32( \pm 0.02)$ \\
\hline
\end{tabular}

Note: values are given as mean ( \pm standard deviation)

\section{INVERSE ANALYSIS APPROACH}

The inverse analysis procedure used, to obtain the tension softening diagram $(\sigma-\mathrm{w})$ from the notched beam (P-CMOD) data, follows Olesen's formulation [19].

The analysis is repeated for different $\sigma-\mathrm{w}$ curves until the P-CMOD response that best fits the experimental data is obtained, as in [9].

The optimization algorithm used here is the probabilistic global search Lausanne (PGSL), which focuses on the search around a set of good solutions to get an optimal solution [20].

The $\sigma-\mathrm{w}$ model is represented by the equation:

$$
\sigma= \begin{cases}\varepsilon \cdot E & \text { precrack state } \\ \sigma_{w}(w)=g(w) \cdot f_{t} & \text { cracked state }\end{cases}
$$

where E - elastic modulus, $\varepsilon$ - elastic strain, $\sigma_{w}(w)-$ stress crack opening relationship with 
$w$ - crack opening and $f_{t}$ - uniaxial tensile strength, and the function $g(w)$ is given by,

$$
g(w)=b_{i}-a_{i} w, \quad w_{i-1}<w<w_{i}=\frac{b_{i+1}-b_{i}}{a_{i+1}-a_{i}}
$$

where $\mathrm{b}_{1}=1, w_{0}=0$ and $w_{i}$ are the limits of the linear branches of the stress-crack opening relationships (Figure 5).
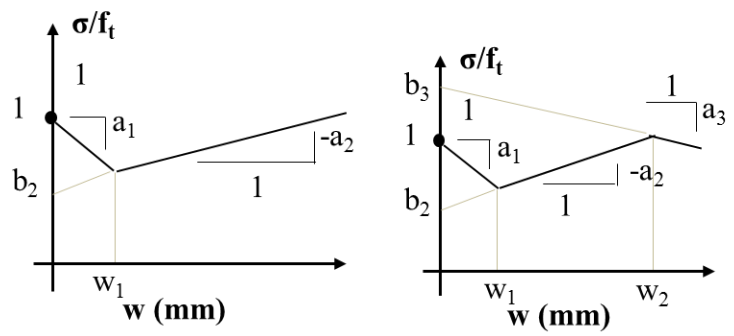

Figure 5: Different analytical models.

\section{RESULTS AND DISCUSSIONS}

A P-CMOD curve for a typical strainhardening type response is compared with those obtained using bilinear and trilinear models in Figure 6. The fit obtained using the trilinear model is significantly better than that with the bilinear model and, therefore, only the trilinear models are discussed hereafter.

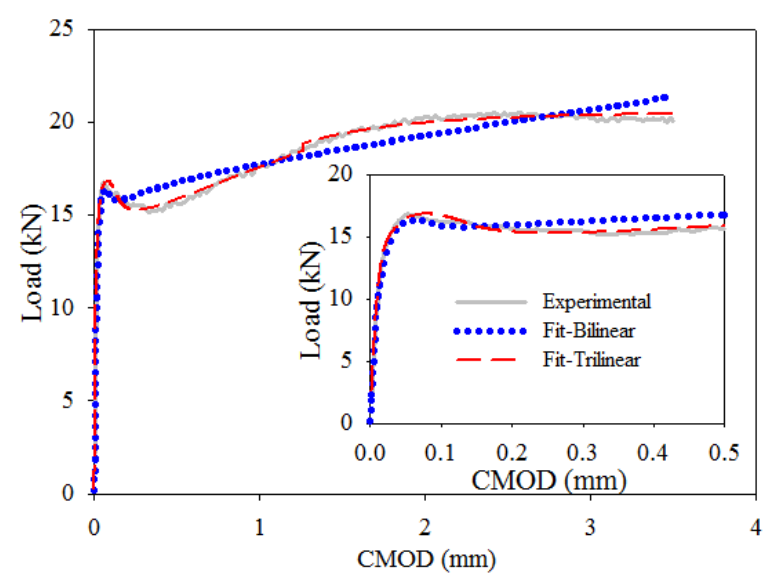

Figure 6: Load-CMOD curves obtained for one specimen of M35SF30_1.

The trilinear $\sigma$-w curves for the SFRC and PFRC are shown in Figures 7 and 8 for different loading rates. It is seen that the bridging stresses $(\sigma)$ increase with the CMOD rate, except in the case of SFRC at the CMOD rate of $10 \mu \mathrm{m} / \mathrm{s}$ (which is in accordance with the P-CMOD curves in Figures 2 and 3). As the CMOD rate increases, there is an upward shift of the curve, which explains the increase in toughness (see Tables 2 and 3).

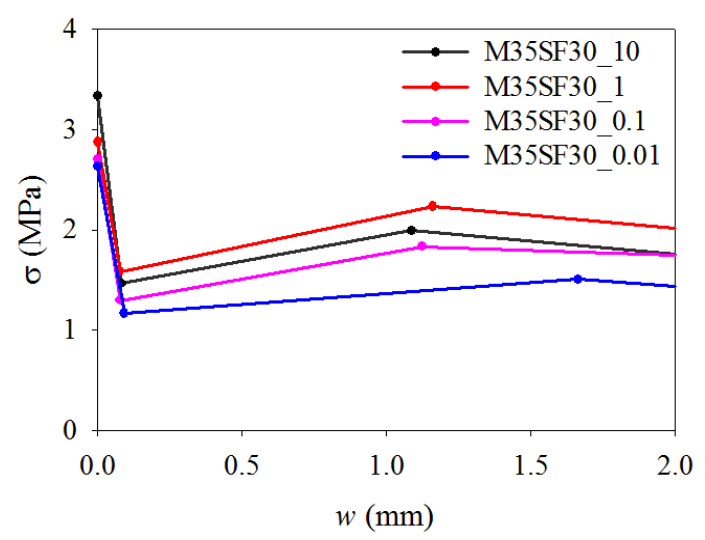

Figure 7: Stress-crack width curves of SFRC at different loading rates.

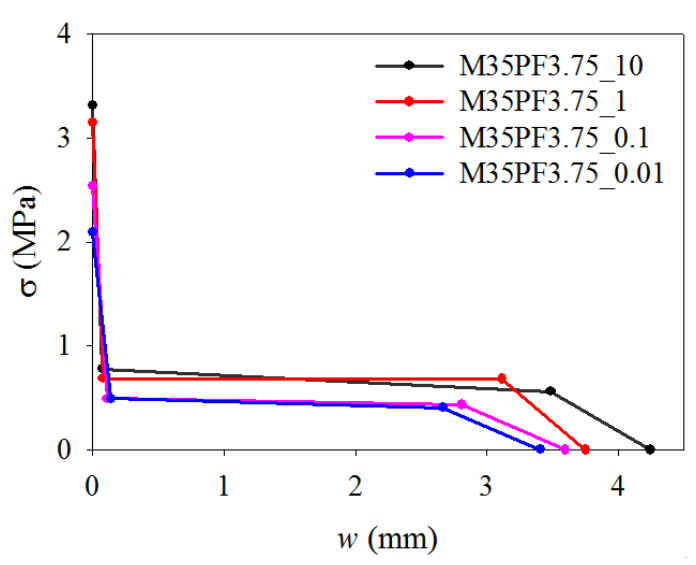

Figure 8: Stress-crack width curves of PFRC at different loading rates.

A reasonable correlation is also found between the flexural strength and the tensile strength obtained from the inverse analysis for both SFRC and PFRC, at different CMOD rates (Figure 9).

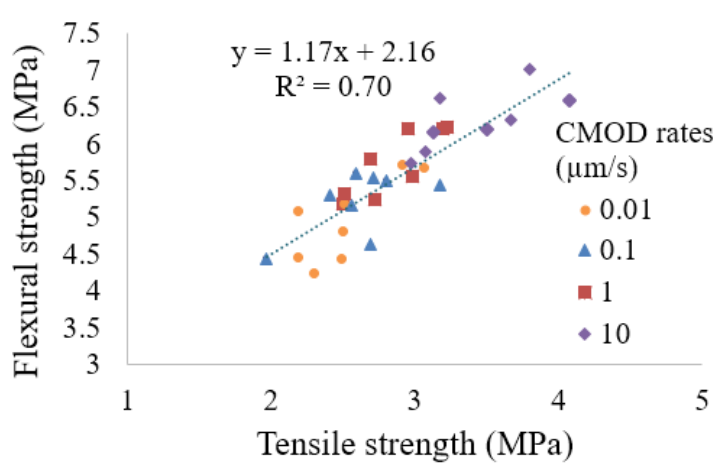

Figure 9: Comparison between flexural and tensile strength of both SFRC and PFRC. 
An attempt has been made to assess the effect of loading rate on the $\sigma$-w curve by considering the stress at the two kinks of the curve, at the crack openings of $\mathrm{w}_{1}$ and $\mathrm{w}_{2}$. It can be seen in Figures 10 and 11 that these stresses do not change significantly with loading rate, though there is a slightly increasing trend. This implies that the cohesive stresses after crack initiation are not sensitive to loading rate.

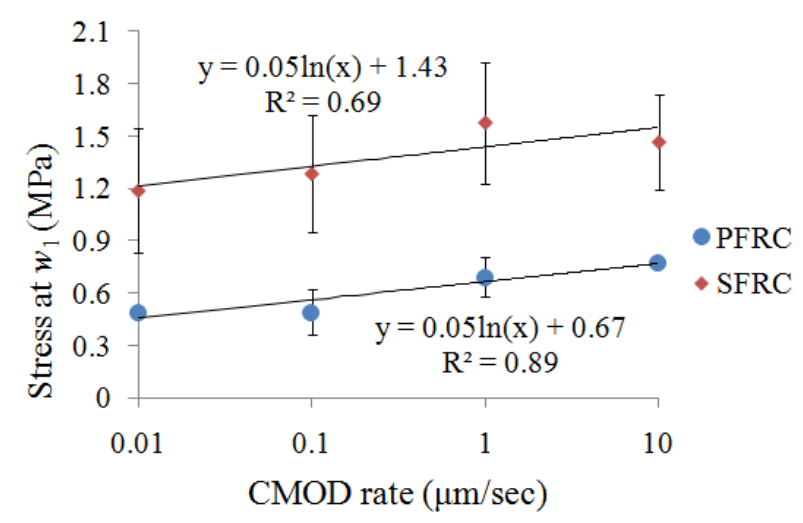

Figure 10: Relationship between stress at a crack opening of $w_{1}$ and CMOD rate.

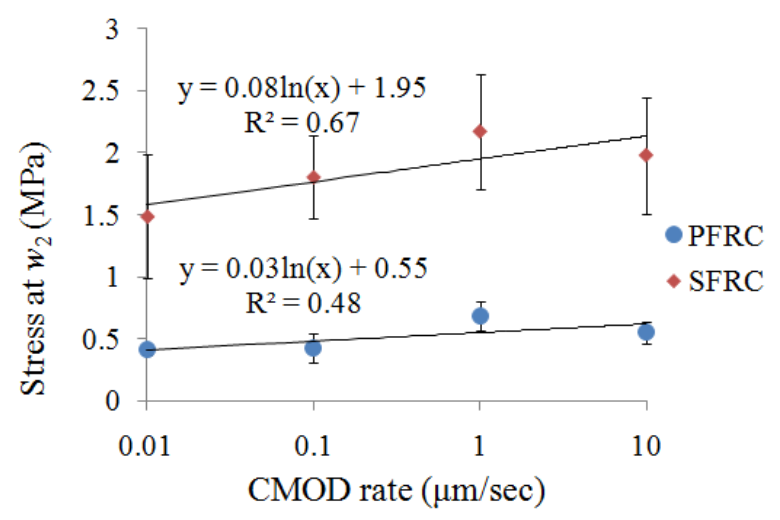

Figure 11: Relationship between stress at a crack opening of $w_{2}$ and CMOD rate.

\section{CONCLUSIONS}

The loading rate dependence of flexural and fracture properties has been examined for FRC. The fracture properties are represented through stress versus crack width curves obtained by an inverse analysis process. Flexural toughness generally increases with the increase in loading rate. However, in the case of SFRC, at the highest loading rate (10 $\mu \mathrm{m} / \mathrm{s}$ ), the toughness seems to be lower than at $1 \mu \mathrm{m} / \mathrm{s}$. This may be due to the rupture of some fibres or multiple crack fronts at higher loading rates instead of the fibres being pulled out. Though the flexural strength and the tensile strength at crack initiation are influenced significantly by the loading rate, the post-peak region is not affected, at least in the range of quasi-static CMOD rates considered here.

\section{REFERENCES}

[1] Jamet, D., Gettu, R., Gopalaratnam, V. S., and Aguado, A. 1995. Toughness of Fiber-Reinforced High-Strength Concrete From Notched Beam Tests, D.J. Stevens et al. (Eds) Testing of Fiber Reinforced Concrete, SP-155; pp. 23-39.

[2] EN 14651-2005. Test method for metallic fibred concrete - Measuring the flexural tensile strength (limit of proportionality (LOP), residual) European specification for sprayed concrete - EFNARC Guidelines.

[3] Buratti, N., Mazzotti, C., and Savoia, M. 2011. Post-cracking behaviour of steel and macro-synthetic fibre-reinforced concretes. Construction and Building Materials, 25:2713-2722.

[4] Jepsen, M. S., Damkilde, L., and Lövgren, I. 2016. A fully general and adaptive inverse analysis method for cementitious materials. Materials and Structures, pp. $1-14$.

[5] Kitsutaka, Y. 1997. Fracture Parameters by Polylinear Tension-Softening Analysis J. Engineering Mechanics, pp. 444-450.

[6] Kooiman, A. G. 2000. Modelling Steel Fibre Reinforced Concrete for Structural Design. Ph.D. Thesis Technical University of Delft.

[7] Löfgren, I., Stang, H., and Olesen, J. F. 2005. Fracture Properties of FRC Determined through Inverse Analysis of Wedge Splitting and Three-Point Bending Tests. J. Advanced Concrete Technology, 3(3):423-434.

[8] Østergaard, L. 2003. Early-Age Fracture Mechanics and Cracking of Concrete. 
Ph.D. Thesis Technical University of Denmark.

[9] Sousa, J. L. A. O., and Gettu, R. 2006. Determining the Tensile Stress-Crack Opening Curve of Concrete by Inverse Analysis. J. Engineering Mechanics, 132(2):141-148.

[10] Uchida, Y., Kurihara, N., Rokugo, K., and Koyanagi, W. 1995. Determination of Tension Softening Diagrams of Various Kinds of Concrete by means of Numerical Analysis. F. H. Witmann (Ed.) Fracture Mechanics of Concrete Structures; pp. 17-30.

[11]Rosa, A. L., Yu, R. C., Ruiz, G., Saucedo, L., and Sousa, J. L. A. O. 2012. A loading rate dependent cohesive model for concrete fracture. Engineering Fracture Mechanics. 82:195-208.

[12] Abd el Aty, M. A. A. 2013. Influence of bending deflection rate on properties of fibrous mortar. HBRC Journal, 9:27-35.

[13]Bažant, Z. P., and Gettu, R. 1992. Rate effects and load relaxation in static fracture of concrete. ACI Materials $J$. 89(5):456-468.

[14]Bernad, C., Gettu, R., Barragán, B. E., and Sousa, J. L. A. O. 2002. Study of the effect of loading rate and relaxation on the behaviour of steel fibre reinforced concrete. Report of tests performed within sub-task 5.2 Creep in the post-cracked region: Brite Project (BRPR.CT98.0813).

[15] Naaman, A. E., and Gopalaratnam, V. S. 1983. Impact properties of steel fibre reinforced concrete in bending. Intnl. J. Cement Composites and Lightweight Concrete, 5(4):225-233.

[16]Zhang, X. X., Abd Elazim, A. M., Ruiz, G., and $\mathrm{Yu}, \quad \mathrm{R}$. C. 2014. Fracture behaviour of steel fibre-reinforced concrete at a wide range of loading rates. Intnl. J. Impact Engineering, 71:89-96.

[17] Malvar, L. J., and Ross, C. A. 1998. Review of strain rate effects for concrete in tension. ACI Materials J. 95(6):735739.

[18] Ghannoum, W., Saouma, V., Haussmann, G., Polkinghome, K., Eck, M., and Kang, D. H. 2012. Experimental investigations of loading rate effects in reinforced concrete columns. J. Struct. Eng., 138(8):1032-1041.

[19] Olesen, J. F. 2001. Fictitious crack propagation in fibre reinforced concrete beams. J. Engineering Mechanics, 127(3):272-280.

[20] Raphael, B., and Smith, I. F. C. 2003. A direct stochastic algorithm for global search. Applied Mathematics and Computation, 146(2-3):729-758. 